\title{
Impact of the COVID-19 Pandemic on Mental Health and Social Support among Adult Egyptians
}

\author{
Safaa M. El-Zoghby ${ }^{1}$ (D) Enayat M. Soltan ${ }^{1}$ (D) $\cdot$ Hend M. Salama ${ }^{1}$ (i)
}

Published online: 28 May 2020

(c) Springer Science+Business Media, LLC, part of Springer Nature 2020

\begin{abstract}
The psychological impact of outbreaks on individuals includes an intense and wide range of psychiatric morbidities. People are likely to experience feelings as; worry about being infected or getting sick, increased self-blame, and helplessness. This study aimed to assess the impact of COVID-19 on mental health and social support among Egyptian adults during the period of the pandemic. This is a cross-sectional observational study using an anonymous online questionnaire. The survey was conducted through a link shared on social networking sites. It was conducted from 2 May 2020 to 9 May 2020. The general populations of the Egyptian adults were included by using convenience and snowball sampling technique (510 adults). Impact Event scale mean $34.3 \pm 15$. About $211(41.4 \%)$ suffered a severe impact. There was an increase in stress from work in $174(34.1 \%)$, financial stress in $284(55.7 \%)$, and stress from home in $320(62.7 \%)$. Half of them felt horrified and helpless in 275 (53.9\%), and 265 (52\%) respectively, while 338 (66.3\%) felt apprehensive. only 24.2\% reported increased support from friends, while increased support from family members in $207(40.6 \%) .46 .5 \%$ shared their feelings with family members, while $176(34.5 \%)$ shared with others. Caring for family members' feelings increased in 330 (64.7\%). Age and rural residency were negative predictors for the impact of event score, while female gender or presence of chronic condition was a positive predictor for the impact of event score. Covid-19 pandemic has a great psychological impact on adult Egyptians and affected social support.
\end{abstract}

Keywords Covid-19 $\cdot$ Egypt $\cdot$ Mental health $\cdot$ Psychological impact $\cdot$ Social support

\section{Introduction}

Coronavirus (COVID-19) a viral outbreak was reported in Wuhan, Hubei Province, China since December 2019 [1], when clusters of pneumonia cases of unknown etiology were reported there [2]. Within few weeks, the number of cases has continued to increase dramatically not just within Wuhan but spread also to other regions of China [3], and on the 11th of March; due to the rapid spread of the infection across the world, the WHO declared the COVID-19 to be a

Hend M. Salama

hind_mikhail@yahoo.com

Safaa M. El-Zoghby

safaaelzoghby86@hotmail.com

Enayat M. Soltan

enayatsoltan@gmail.com

1 Family Medicine Department, Faculty of Medicine, Suez Canal University, Ismailia, Egypt pandemic where the number of affected countries reached 114 country [4].

The COVID-19 infection is so far considered the largest outbreak of atypical pneumonia since the severe acute respiratory syndrome (SARS) outbreak in 2003. It is highly contagious affecting a large number of populations where the total number of cases and deaths since its beginning surpassed those of SARS or any of its ancestors [5]. It was estimated by the WHO that, by the end of March 2020 the total number of confirmed cases from 204 countries around the world had exceeded 600,000 and that of confirmed deaths across the globe exceeded 33,000 [6].

In similarity with SARS, COVID-19 is a beta-coronavirus, and its full genetic sequence isolated from the early human cases in China as well as subsequent ones from cases all over the world showed that COVID-19 has an ecological origin in bats [7]. However, the actual route of transmission is still controversial, as usually close contact between human and bats is limited, suggesting that transmission has happened through another intermediate animal host or zoonotic 
source that could be a domestic animal, a wild animal, or a domesticated wild animal which has not been yet known [8].

Evidence provided from published studies showed that human-to-human transmission occurs from symptomatic people to others who are in close contact through virus-laden respiratory droplets, direct contact with infected persons, or by contact with contaminated objects and surfaces [9]. Studies also showed that early in the 1 st 3 days from onset of symptoms, shedding of the virus is highest in the upper respiratory tract, where people; as suggested by preliminary data become more contagious in comparison to the late onset of the disease [10].

Since the beginning of the infection, most governments took quick actions trying to slow down the virus spread. A state of lockdown was imposed in many countries around the world, travel was restricted, there was social isolation where people stayed at home, and working from home was the case for many employees [5].

In Egypt, by the beginning of April 2020, there were over 800 confirmed cases, with more than 50 fatalities, and a rapid tendency towards increase [11]. Over about one month, the number of confirmed cases increased tremendously to reach 6465 cases on the 3rd of May 2020, with about 430 fatality cases; a jump that can cause anxiety and fear to the general population [12].

Many researchers studied the psychological impact of outbreaks on the individual, showing an intense and wide range of psychiatric morbidities [13]. People are likely to experience feelings as; worry about being infected or getting sick, increased self-blame, and helplessness [14]. Besides, high morbidity and mortality rates, resource instability, fear of stigma and discrimination, besides experiences with infected people, are all risk factors for depression and anxiety and can cause negative outcomes on mental health during these periods [15].

With the ongoing research on COVID-19, and being a new disease, many facts continue to change incessantly. Parallel to this, a lot of myths and fake news arise in the general public, and with the extensive use of social media, they prevail greatly causing more fear, confusion, and anxiety among the population [4].

Considering the mental health issues as a major health concern during the ongoing COVID-19 pandemic is crucial. It is indispensable to study how people are coping with such a major disaster and to appropriately understand their mental health status [16]. The ongoing COVID-19 epidemic is inducing fear, and a timely understanding of mental health status is urgently needed for society [17].

Most of the recently published research related to COVID-19 focused on topics as epidemiology, clinical symptoms, genetic characteristics of the virus, and its spread $[18,19]$. However, there is a paucity of information on the psychological impact and mental health of the general population, although the anxiety and concerns in society are globally affecting every individual to variable extents during this pandemic [5].

Therefore, this present study aims to assess the impact of COVID-19 on mental health and social support among Egyptian adults during the period of the pandemic, in an attempt to help in conserving the psychological wellbeing of the community, particularly with its expansion in Egypt and other countries of the world, and the uncertainty surrounding it.

\section{Subjects and Methods}

\section{Study Design and Population}

This is a cross-sectional observational study to assess the public's psychological response during the pandemic of COVID-19 by using an anonymous online questionnaire. The survey was conducted through a link shared on social networking sites. It was conducted from 2 May 2020 to 9 May 2020. The general populations of the Egyptian adults who fulfilled the inclusion criteria and agreed to participate in the study were included by using convenience and snowball sampling technique (510 adults).

\section{Inclusion and Exclusion Criteria}

Egyptians of both sexes aged 18 years or more, able to understand and read Arabic, who use social media, and willing to give informed consent were included. While those living in Egypt from other nationalities, and those who are known to have any psychiatric illness or refused to share in the study were excluded.

\section{Study Tools}

The semi-structured questionnaire consisted of four parts:

1 Socio-demographic characteristics: including; age, gender, residence, level of education, employment status, or working in the medical field, marital status, and presence of any chronic diseases.

2 Impact of Event Scale-Revised (IES-R): It is a selfadministered questionnaire that has been validated in Arabic for determining the extent of psychological impact after exposure to a public health crisis $[5,20$, $21]$. It is consisted of 22-items and composed of three subscales and aims to measure the mean avoidance, intrusion, and hyperarousal. It is very helpful in measuring the effect of routine life stress, everyday traumas, and acute stress. The total IES-R score was divided into 0-23 (normal), 24-32 (mild psychological impact), 
33-36 (moderate psychological impact), and $>37$ (severe psychological impact) [22]. Items were scored on Likert 5-point scales 0 for Not at all, 1 for a little bit, 2 for moderately, 3 for quite a bit, and 4 for extremely.

3 Indicators of negative mental health impact: these are six modified and validated questions regarding negative mental health impacts resulting from the pandemic was used; these questions had a Cronbach's alpha of 0.88 [23]. The domains assess changes in stress from work, financial stress, stress from home, horrified feelings due to the COVID-19 pandemic, apprehensive feelings due to the COVID-19 pandemic, and helpless feelings due to the COVID-19 pandemic (response options for each: decreased, unchanged/same as before, and increased).

4 Impact on social and family support: Investigating the impact of the COVID-19 pandemic on social and family support through modified and validated reliable questionnaire (Cronbach's alpha of 0.87). The five questions in this questionnaire evaluated support from friends, support from family members, sharing feelings with other family members, sharing feelings with others, and caring for family members' feelings [23]. The response options for these questions were as follows: decreased, unchanged/same as before, and increased, where lower score indicated lower social and family support.

\section{Validation and Pilot Study}

Using accepted guidelines for translation-back-translation. The Indicators of negative mental health impact and Impact on social and family support questionnaires were translated into Arabic. It was back-translated into English by a bilingual consultant, and then both translators counsel for necessary modifications, restatement, and rewording then the questionnaire face validated by three expert opinions with no major modifications. A pilot study carried out on 22 participants before the study to assess the feasibility and reliability of the questionnaire, with acceptable Cronbach's $\alpha$ of 0.7 .

\section{Data Collection}

Data collected through an online semi-structured questionnaire using Google forms with a consent form included with it. The link to the questionnaire was sent through emails, WhatsApp groups, Facebook groups, and other social media. The participants were encouraged to roll out the survey to more people as they could. On receiving and clicking the link the participants will be directed to the information about the study and informed consent. After they accept to take the survey they will fill up the demographic details. Then a set of several questions will appear consecutively, in which the participants will answer.

\section{Outcome Variables}

Psychological impact of the event (IES), Negative mental health impacts, and Impact on social and family support.

\section{Statistical Analysis}

Statistical analysis was performed using Statistical Package for the Social Sciences (SPSS V20.0). The normal distribution of the continuous data was checked using the Shapiro Wilk test. Descriptive statistics: normally distributed data were expressed by mean and Standards deviation. Frequencies and percentages calculated and tabulated. Inferential statistics: independent student t-test, ANOVA, and Chisquare tests used. Multivariable linear regression analysis was used to assess predictors of the Impact of Event Scale (IES). A p-value of $<0.05$ was considered statistically significant.

\section{Research Ethics}

The Ethics Committee of Faculty of Medicine, Suez Canal University approved the study (Code 4171\#). Informed consent was obtained from all participants included in the study. No monetary rewards were given for completing the questionnaire.

\section{Results}

The study included 510 participants of adult Egyptians, about half of sample 232 (45.5\%) aged from 18 to 30 years old, and about two-thirds of the sample were females and married $336(65.9 \%)$, and 307 (60.2\%) respectively. The majority of participants were well educated have bachelor $297(58.2 \%)$ or postgraduate degrees 170 (33.3\%). Also, a Fifth of the sample was working in the medical field $106(20.8 \%)$. About half of them work as a governmental employee 233 (45.7\%). Most of the sample live in urban areas $456(89.4 \%)$. Only $96(18.8 \%)$ of them suffer from chronic diseases (Table 1).

Table 2 shows the psychological impact of Covid-19 pandemic as Impact Event scale mean \pm SD was $34.25 \pm 15$, Intrusion domain $13.68 \pm 6.9$, avoidance mean $12.83 \pm 6.19$, while hyperarousal domain was $7.73 \pm 5.21$. Also, 211 (41.4\%) of the sample suffered a severe impact, 54 (10.6\%) moderately affected, while $122(23.9 \%)$ mildly affected. About a third of the sample reported increased stress from work 174 (34.1\%), while half of the sample suffered increased financial stress $284(55.7 \%)$, also two-thirds of the study sample suffered increased stress from home 320 (62.7\%). Half of the participants felt horrified and helpless due to Covid-19 pandemic 275 (53.9\%), and 265 (52\%) 
Table 1 Socio-demographic characteristics of the sample $(n=510)$

\begin{tabular}{|c|c|c|}
\hline Variable & Count & $\%$ \\
\hline \multicolumn{3}{|l|}{ Age } \\
\hline $18-30$ years & 232 & 45.5 \\
\hline $31-40$ years & 216 & 42.4 \\
\hline $41-50$ years & 48 & 9.4 \\
\hline $51-60$ years & 10 & 2.0 \\
\hline More than 60 years & 14 & 2.7 \\
\hline \multicolumn{3}{|l|}{ Gender } \\
\hline Male & 174 & 34.1 \\
\hline Female & 336 & 65.9 \\
\hline \multicolumn{3}{|l|}{ Marital status } \\
\hline Single/divorced & 203 & 39.8 \\
\hline Married & 307 & 60.2 \\
\hline \multicolumn{3}{|l|}{ Education } \\
\hline$\leq$ Secondary school & 43 & 8.4 \\
\hline High education (Bachelors) & 297 & 58.2 \\
\hline Post-graduate degrees & 170 & 33.3 \\
\hline \multicolumn{3}{|l|}{ Work in medical field } \\
\hline No & 404 & 79.2 \\
\hline Yes & 106 & 20.8 \\
\hline \multicolumn{3}{|l|}{ Occupation status } \\
\hline Unemployed/manual worker & 183 & 35.9 \\
\hline Governmental employee & 233 & 45.7 \\
\hline Private employee & 94 & 18.4 \\
\hline \multicolumn{3}{|l|}{ Residency } \\
\hline Urban & 456 & 89.4 \\
\hline Rural & 54 & 10.6 \\
\hline \multicolumn{3}{|l|}{ History of chronic disease } \\
\hline No & 414 & 81.2 \\
\hline Yes & 96 & 18.8 \\
\hline
\end{tabular}

respectively, while two-thirds of sample 338 (66.3\%) felt apprehensive due to it.

About social support, only one-quarter of individuals reported increased support from friends 123 (24.1\%), while a higher percent received increased support from family members 207 (40.6\%). About half of the persons shared their feelings with family members 237 (46.5\%), and a lower percent shared their feelings with others when in blue 176 (34.5\%). However; caring for family members' feelings increased in two-thirds of sample 330 (64.7\%).

Table 3 shows that younger persons, females, and university-educated people reported a higher psychological impact than older, males, or well educated with post-graduate degrees. Persons working in the medical field reported a lower psychological impact than others. Also, people live in urban areas, or having chronic diseases have higher psychological impact scores.

Age and rural residency were negative predictors for the impact of event score, while female gender or presence of
Table 2 Psychological (IES) and negative health impacts of Covid-19 and changes of family and social support of the sample $(n=510)$

\begin{tabular}{lll}
\hline Variable & & \\
\hline Psychological Impact Total and Domains scores (IES) & & \\
Total IES score (Mean \pm SD) & 34.25 & 15.0 \\
Intrusion (Mean \pm SD) & 13.68 & 6.90 \\
Avoidance (Mean \pm SD) & 12.83 & 6.19 \\
Hyperarousal (Mean \pm SD) & 7.73 & 5.21 \\
Psychological Impact severity (IES) & & \\
Normal (N \%) & 123 & 24.1 \\
Mild impact (N \%) & 122 & 23.9 \\
Moderate impact (N \%) & 54 & 10.6 \\
Severe impact (N \%) & 211 & 41.4 \\
Negative Health Impact & & \\
Increased stress from work (N \%) & 174 & 34.1 \\
Increased financial stress (N \%) & 284 & 55.7 \\
Increased stress from home (N \%) & 320 & 62.7 \\
Feel horrified due to the COVID-19 (N \%) & 275 & 53.9 \\
Feel apprehensive due to COVID-19 (N \%) & 338 & 66.3 \\
Feel helpless due to the COVID-19 (N \%) & 265 & 52.0 \\
Improvement in Family and Social support & & \\
Getting support from friends (N \%) & 123 & 24.1 \\
Getting support from family members (N \%) & 207 & 40.6 \\
Shared feeling with family Members (N \%) & 237 & 46.5 \\
Shared feeling with others when in blue (N \%) & 176 & 34.5 \\
Caring for family members' feelings (N \%) & 330 & 64.7 \\
\hline
\end{tabular}

chronic condition was a positive predictor for the impact of event score (Table 4).

Table 5 shows a significant relationship between being a married person and the increased financial and home stresses in the period of the Covid-19 pandemic. Females felt more horrified than males, also females and married people felt more apprehensive than others. Furthermore; females and younger persons felt helpless due to pandemic. Finally, females and married subjects cared more for family members' feelings.

\section{Discussion}

The present study was designed to investigate the impact of COVID-19 on mental health and social support among Egyptian adults during the period of the pandemic. Up to our knowledge, this study is one of the first studies to discuss such matters in Egypt and the Arab world [24]. Since the virus is in the ongoing spread, and the numbers of cases and fatalities are increasing, we hypothesized that the pandemic will cause negative psychological impact with more stress and anxiety among the general population. 
Table 3 Psychological Impact (IES) of Covid-19 pandemic according to sociodemographic factors

\begin{tabular}{|c|c|c|c|}
\hline Variable & IES score mean (SD) & $\mathrm{t} / \mathrm{F}^{* *}$ & $P$ value \\
\hline \multicolumn{4}{|l|}{ Age } \\
\hline$\leq 30$ years & $36.12(15.62)$ & 2.562 & $0.01 *$ \\
\hline$>30$ years & $32.71(14.32)$ & & \\
\hline \multicolumn{4}{|l|}{ Gender } \\
\hline Male & $30.80(16.59)$ & 3.782 & $<0.0001 *$ \\
\hline Female & $36.05(13.86)$ & & \\
\hline \multicolumn{4}{|l|}{ Marital status } \\
\hline Single/divorced & $35.19(15.32$ & 1.140 & 0.25 \\
\hline Married & $33.64(14.84)$ & & \\
\hline \multicolumn{4}{|l|}{ Education } \\
\hline$\leq$ Secondary school & $32.35(18.63)$ & $3.251 * *$ & $0.04 *$ \\
\hline $\begin{array}{l}\text { High education (Bach- } \\
\text { elors) }\end{array}$ & $35.69(15.55)$ & & \\
\hline Post- graduate studies & $32.24(12.75)$ & & \\
\hline \multicolumn{4}{|l|}{ Work in Medical Field } \\
\hline No & $34.96(15.56)$ & 2.071 & $0.04 *$ \\
\hline Yes & $31.57(12.53)$ & & \\
\hline \multicolumn{4}{|l|}{ Residency } \\
\hline Urban & $35.11(14.68)$ & 3.791 & $<0.0001^{*}$ \\
\hline Rural & $27.02(16.17)$ & & \\
\hline \multicolumn{4}{|l|}{ History of chronic disease } \\
\hline No & $33.55(14.52)$ & 2.225 & $0.03 *$ \\
\hline Yes & $37.32(16.81)$ & & \\
\hline
\end{tabular}

*Statistically significant $(\mathrm{P}<0.05)$

**Anova test

The psychological impact that was assessed through the IES-R score manifested a mean score of 34.25, where more than half of the participants $(52 \%)$ showed moderate and severe psychological impact, whilst $23.9 \%$ reported mild impact. This result conforms with that mentioned in one study conducted in China by Wang et al. in 2020 during the initial state of the virus spread -using the same scale- where $53.8 \%$ of the participants stated moderate or severe psychological impact and $21.7 \%$ reported mild impact [5].

However, this result is much higher than that found by Zhang et al. in their study that was -also- conducted in China in 2020 [16], as the overall mean IES score in their participants was 13.6 , indicating a mild stressful impact, with only $7.6 \%$ of the study group had an IES score $\geq 26$. This variation may be related to the smaller sample size in that study (263 participants) and the fact that it was conducted only on those living in Jinzhou, Liaoning Province, mainland China.

Our study revealed that; females, younger persons, and those with chronic illnesses reported higher psychological impacts. Moreover; being female or having chronic conditions was found to be a positive predictor for the impact of event score, whilst age and rural residency were identified as negative predictors. These results are congruent to previous studies in China and Italy which revealed that females are more vulnerable to stress than their male peers, and that young age has more tendency to be elicited by the surrounding stressors [5, 25]. Likewise, previous studies mentioned that those with chronic illnesses are more susceptible to psychological distresses as they perceive themselves with poor health and more liable to get diseased, as assumed by some authors [25, 26].

Similarly, university-educated people reported a higher psychological impact than those with post-graduate degrees. This is in opposition to that found by other researchers where they suppose that highly educated people might be more stressed due to their higher self-awareness [27]. However, we postulate that raised awareness can increase the taken protective measures and the needed procedures in case of suspected infection, which can decrease the sense of stress. This also could explain the lower psychological impact in our study to those working in the medical field, a result that

Table 4 Best fitting multiple linear regression model for IES score

\begin{tabular}{|c|c|c|c|c|c|c|c|}
\hline & \multicolumn{2}{|c|}{ Unstandardized coefficients } & \multirow{2}{*}{$\begin{array}{l}\text { Standardized } \\
\text { coefficients } \\
\text { Beta }\end{array}$} & \multirow[t]{2}{*}{$\mathrm{t}$} & \multirow[t]{2}{*}{ Sig. } & \multicolumn{2}{|c|}{$95.0 \%$ confidence interval for B } \\
\hline & $\mathrm{B}$ & Std. error & & & & Lower bound & Upper bound \\
\hline (Constant) & 43.995 & 7.691 & & 5.720 & 0.000 & 28.885 & 59.105 \\
\hline Age & -2.037 & 0.966 & -0.106 & -2.108 & $0.036^{*}$ & -3.935 & -0.138 \\
\hline Gender (male) & 4.266 & 1.412 & 0.135 & 3.022 & $0.003^{*}$ & 1.493 & 7.040 \\
\hline Residency (urban) & -7.289 & 2.170 & -0.149 & -3.359 & $0.001^{*}$ & -11.551 & -3.026 \\
\hline Marital status & 0.500 & 1.502 & 0.016 & 0.332 & 0.740 & -2.452 & 3.451 \\
\hline Education & -0.448 & 1.116 & -0.019 & -0.401 & 0.689 & -2.641 & 1.746 \\
\hline Work in Medical Field & -3.397 & 1.743 & -0.092 & -1.949 & 0.052 & -6.822 & 0.027 \\
\hline Chronic disease & 4.299 & 1.688 & 0.112 & 2.547 & $0.011^{*}$ & 0.983 & 7.616 \\
\hline
\end{tabular}

r-square $=0.78$. Model ANOVA: $F=6.047, p \leq 0.001$. All variables entered

* Statistically significant $(\mathrm{P}<0.05)$ 
Table 5 Negative health impact and social support changes according to sociodemographic factors $(\mathrm{n}=510)$

\begin{tabular}{|c|c|c|c|c|c|c|c|c|c|}
\hline \multirow[t]{2}{*}{ Variable } & \multicolumn{3}{|l|}{ Gender } & \multicolumn{3}{|l|}{ Age } & \multicolumn{3}{|l|}{ Marital status } \\
\hline & $\begin{array}{l}\text { Male } \\
174 \\
\mathrm{~N}(\%)\end{array}$ & $\begin{array}{l}\text { Female } \\
336 \\
\mathrm{~N}(\%)\end{array}$ & P-value & $\begin{array}{l}18-30 \\
232 \\
N(\%)\end{array}$ & $\begin{array}{l}>30 \\
278 \\
N(\%)\end{array}$ & $\mathrm{P}$-value & $\begin{array}{l}\text { Single/ } \\
\text { divorced } 203 \\
\mathrm{~N}(\%)\end{array}$ & $\begin{array}{l}\text { Married } \\
307 \\
\mathrm{~N}(\%)\end{array}$ & P-value \\
\hline Increased work stress & $56(32.2)$ & $\begin{array}{l}118 \\
(35.1)\end{array}$ & 0.5 & $78(33.6)$ & $96(34.5)$ & 0.8 & $72(35.5)$ & $102(33.2)$ & 0.6 \\
\hline Increased financial stress & $103(59.1)$ & $181(53.9)$ & 0.2 & $122(52.6)$ & $162(58.3)$ & 0.2 & $97(47.8)$ & $187(60.9)$ & $0.003 *$ \\
\hline Increased home stress & $102(58.6)$ & $218(64.9)$ & 0.2 & $141(60.8)$ & $79(64.4)$ & 0.4 & $110(54.2)$ & $210(68.4)$ & $0.001 *$ \\
\hline Feel horrified & $79(45.4)$ & $196(58.3)$ & $0.005^{*}$ & $133(57.3)$ & $142(51.1)$ & 0.2 & $102(50.2)$ & $173(56.4)$ & 0.2 \\
\hline Feel apprehensive & $95(54.6)$ & $243(72.3)$ & $<0.001^{*}$ & $157(67.7)$ & $181(65.1)$ & 0.5 & $122(60.1)$ & $216(70.4)$ & $0.16^{*}$ \\
\hline Feel helpless & $72(41.4)$ & $193(57.4)$ & $<0.001^{*}$ & $134(57.8)$ & $131(47.1)$ & $0.02 *$ & $101(49.8)$ & $164(53.4)$ & 0.4 \\
\hline Friends support & $34(19.5)$ & $89(26.5)$ & 0.8 & $62(26.7)$ & $61(21.9)$ & 0.2 & $50(24.6)$ & $73(23.8)$ & 0.8 \\
\hline Family support & $71(40.8)$ & $136(40.5)$ & 0.9 & $95(40.9)$ & $112(40.3)$ & 0.8 & 75 (36.9) & $132(43.0)$ & 0.2 \\
\hline Family sharing & $79(45.4)$ & $158(47.0)$ & 0.7 & $103(44.4)$ & $134(48.2)$ & 0.4 & 85 (41.9) & $152(49.5)$ & 0.9 \\
\hline Others sharing & $54(31.0)$ & $122(36.3)$ & 0.2 & $84(36.2)$ & $92(33.1)$ & 0.4 & $69(34.0)$ & $107(34.9)$ & 0.8 \\
\hline Caring family & $100(57.4)$ & $230(68.5)$ & $0.01 *$ & $140(60.3)$ & $190(68.3)$ & 0.06 & $111(54.7)$ & $219(71.3)$ & $<0.001 *$ \\
\hline
\end{tabular}

* Statistically significant $(\mathrm{P}<0.05) \mathrm{X}^{2}$ test

reiterates those found in a former study by Mishra et al. in 2016 which indicated that health care workers usually have better awareness, with favorable attitude during pandemics and low levels of anxiety [28].

It was also found that more than half of the participants felt horrified and apprehensive due to COVID-19, a result that adheres to that found in other studies in both India and China which revealed a sense of panic by the general public regarding the pandemic $[4,16]$, and accords to that found in the literature revealing that stress levels increase during epidemics [29].

Our study also showed an increase in the negative health impact of the pandemic on the studied population with increased stress from work and home, together with increasing financial stress. These results are in contrast to that found in the study conducted in China by Zhang et immediately after the COVID-19 spread, where most of the participants didn't state increasing stress in the mentioned fields, a matter that was attributed by the author to the time of the study itself where the impact of the disease was still not severe as later on after conducting his study [16].

On studying the association between socio-demographic characteristics and the negative health impact, it was found that married persons experienced increased financial and home stresses and felt more apprehensive during the pandemic. Correspondingly, females also felt more apprehensive, more horrified and helpless than males, in a like manner with younger persons who felt helpless due to the pandemic.

The latter result is in similarity to that found by Zhang et al. in his study, where there was a significant association between different age groups and feeling helpless
$(P=0.049)$. However, contrary to our study, other sociodemographic variables including gender and marital status had no relation to the indicators of negative mental health impact [16].

Our study revealed that overall there was an increase in social and family support in our participants; where they become more likely to share their feelings and have a substantial increase in taking care for the feelings of the family members, especially females and married persons, where an association was found between these two variables with caring more for family members' feelings. These results are in line with the findings of the previous studies which manifested that social support increases during the time of pandemics [4, 16], a finding that was linked by some authors to the nature of the slow motion of the whole universe during these periods, giving more chance for people to connect and support each other [23, 29].

\section{Limitations of the Study}

Most of the study participants were educated, so we cannot generalize results for less educated. Also, it included people who have access to social media; no data about illiterate and very poor people.

\section{Conclusions}

Covid-19 pandemic has a great psychological impact on adult Egyptians and highly affected social support. The most affected groups were younger, females, married, not well educated, not working in the medical field, live in 
urban areas, or have a chronic disease. It caused increased stress regarding work, home, and finances. Also pandemic increased the feelings of being horrified, apprehensive, or helpless. However; it increased caring for family members' feelings in many subjects.

Acknowledgements The authors would like to acknowledge all the participants for their co-operation

\section{Funding None.}

\section{Compliance with Ethical Standards}

Conflict of interest The authors declare that they have no conflict of interest.

Ethical Approval All procedures performed in the study were following the ethical standards of the institutional research committee of Faculty of Medicine Suez Canal University and with the 1964 Helsinki declaration and its later amendments.

Informed Consent Informed consent was obtained from all individual participants included in the study.

\section{References}

1. Holshue, M. L. (2020). First case of 2019 novel coronavirus in the United States. New England Journal of Medicine. https://doi. org/10.1056/NEJMoa2001191

2. Hawryluck, L. (2004). SARS control and psychological effects of quarantine, Toronto, Canada. Emerging Infectious Diseases, 10(7), 1206.

3. Wang, C. (2020). A novel coronavirus outbreak of global health concern. The Lancet, 395(10223), 470-473.

4. Roy, D. (2020). Study of knowledge, attitude, anxiety \& perceived mental healthcare need in Indian population during COVID-19 pandemic. Asian Journal of Psychiatry. https://doi.org/10.1016/j. ajp.2020.102083

5. Wang, C. (2020). Immediate psychological responses and associated factors during the initial stage of the 2019 coronavirus disease (COVID-19) epidemic among the general population in China. International Journal of Environmental Research and Public Health, 17(5), 1729.

6. World Health Organization. (2020). Coronavirus disease 2019 (COVID-19): Situation report, 61.

7. Paules, C. I., Marston, H. D., \& Fauci, A. S. (2020). Coronavirus infections: More than just the common cold. JAMA, 323(8), 707-708.

8. World Health Organization. (2020). Coronavirus disease 2019 (COVID-19): Situation report, 94.

9. Ong, S. W. X. (2020). Air, surface environmental, and personal protective equipment contamination by severe acute respiratory syndrome coronavirus 2 (SARS-CoV-2) from a symptomatic patient. JAMA., 323, 1610-1612.

10. Liu, Y. (2020). Viral dynamics in mild and severe cases of COVID-19. The Lancet Infectious Diseases. https://doi. org/10.1016/S1473-3099(20)30232-2

11. Abdelhafiz, A. S. (2020). Knowledge, perceptions, and attitude of egyptians towards the novel coronavirus disease (COVID-19). Journal of Community Health. https://doi.org/10.1007/s 1090 0-020-00827-7
12. https://www.care.gov.eg/EgyptCare/Index.aspx. Egyptian statistics on COVID-19. 2020 [cited 20203 May].

13. Sim, K. (2010). Psychosocial and coping responses within the community health care setting towards a national outbreak of an infectious disease. Journal of Psychosomatic Research, 68(2), 195-202.

14. Van Bortel, T. (2016). Psychosocial effects of an Ebola outbreak at individual, community and international levels. Bulletin of the World Health Organization, 94(3), 210.

15. Brooks, S. K. (2020). The psychological impact of quarantine and how to reduce it: rapid review of the evidence. The Lancet. https ://doi.org/10.1016/S0140-6736(20)30460-8

16. Zhang, Y., \& Ma, Z. F. (2020). Impact of the COVID-19 pandemic on mental health and quality of life among local residents in Liaoning Province, China: A cross-sectional study. International Journal of Environmental Research and Public Health, 17(7), 2381.

17. Xiang, Y. T. (2020). Timely mental health care for the 2019 novel coronavirus outbreak is urgently needed. The Lancet Psychiatry, $7(3), 228-229$.

18. Huang, C. (2020). Clinical features of patients infected with 2019 novel coronavirus in Wuhan, China. The Lancet, 395(10223), 497-506.

19. Lu, R. (2020). Genomic characterisation and epidemiology of 2019 novel coronavirus: Implications for virus origins and receptor binding. The Lancet, 395(10224), 565-574.

20. Zhang, M. W. (2014). Usage of social media and smartphone application in assessment of physical and psychological wellbeing of individuals in times of a major air pollution crisis. JMIR mHealth and uHealth, 2(1), e16.

21. Agostini, T. (2018). The arabic impact of event scale-revised: Psychometric properties in a sample of Syrian refugees. In 13th Alps Adria Psychology Conference. 2018: Horizons of Psychology.

22. Creamer, M., Bell, R., \& Failla, S. (2003). Psychometric properties of the impact of event scale: Revised. Behaviour Research and Therapy, 41(12), 1489-1496.

23. Lau, J. T. (2006). Positive mental health-related impacts of the SARS epidemic on the general public in Hong Kong and their associations with other negative impacts. Journal of Infection, 53(2), 114-124.

24. Arnout, B. A. (2020). The effects of corona virus (COVID-19) outbreak on the individuals' mental health and on the decision makers: A comparative epidemiological study. Health Sciences, 9(3), 26-47.

25. Mazza, C. (2020). A nationwide survey of psychological distress among italian people during the COVID-19 pandemic: Immediate psychological responses and associated factors. International Journal of Environmental Research and Public Health, 17(9), 3165.

26. Hatch, R. (2018). Anxiety, depression and post traumatic stress disorder after critical illness: A UK-wide prospective cohort study. Critical Care, 22(1), 310.

27. Qiu, J. (2020). A nationwide survey of psychological distress among Chinese people in the COVID-19 epidemic: implications and policy recommendations. General Psychiatry, 33(2), e100213.

28. Mishra, P. (2016). Knowledge, attitude and anxiety towards pandemic flu a potential bio weapon among health professionals in Indore City. Przeglad Epidemiologically, 70(1), 41-45.

29. Lau, J. T. (2005). Impacts of SARS on health-seeking behaviors in general population in Hong Kong. Preventive Medicine, 41(2), $454-462$.

Publisher's Note Springer Nature remains neutral with regard to jurisdictional claims in published maps and institutional affiliations. 